\title{
The Impact of XBRL: A Delphi Investigation
}

\author{
Amelia A. Baldwin. University of Arkansas - Fort Smith. USA. abaldwin@uafortsmith.edu
}

Brad S. Trinkle. College of Charleston - School of Business. USA. trinkleb@ cofc.edu

\begin{abstract}
This project attempts to add to the extant research by presenting the results of a future forecasting Delphi study that addresses the impacts of XBRL in the second decade of the new millennium. The future impacts of XBRL [eXtensible Business Reporting Language] on financial reporting were studied using the Delphi technique. The Delphi panel suggests that XBRL is very likely to impact corporations, financial reporting, users of financial reports and auditing. The most likely impacts of XBRL include: increased accessibility of financial reports, easier regulatory compliance, enhanced availability of financial reports, facilitation of continuous reporting, and improved efficiency in investment and business decision making.
\end{abstract}

Keywords: XBRL, financial reporting, technology impacts, Delphi technique, accounting regulation.

\section{INTRODUCTION}

A poll of leading information technology consultants, futurists and financial officers identified XBRL [eXtensible Business Reporting Language] as one of the seven cutting edge technologies expected to have a large impact on business and to revolutionize corporate performance (The Futurist 2003). XBRL has been identified by AICPA [American Institute of Certified Public Accountants] and FEI [Financial Executives Institute] leaders as an important initiative shaping the future of the profession (Harrington 2005) and has been mentioned for several years on the AICPA's top ten technologies list (AICPA 2006). The use of a universal business reporting language has been called for by many individuals and organizations (Lymer et al. 1999). Users want more flexibility, ease of use and timeliness in financial reporting (FASB 2000; CICA 
1999; AICPA 1994). Recent business scandals and the passage of the Sarbanes-Oxley Act in the U.S. have created a ripe environment for the improvement of information quality via XBRL adoption (Elysée et al. 2004). Clearly, sweeping changes are ahead (Spaul 1997, ICAEW 1998, Ettredge et al. 2002).

Currently, over 500 companies, organizations and regulatory agencies are involved in the development of XBRL (XBRL 2010b). Two dozen countries, in addition to the International Accounting Standards Board, have formally established or are in the process of establishing XBRL jurisdictions (XBRL 2010a). Calls for the adoption of XBRL for electronic filing and efforts to make it happen are occurring in such disparate locations as India (Vasal and Srivastava 2005), Japan (XBRL Japan 2005), Ireland, China and South Africa (XBRL 2010b).

A U.S. Securities \& Exchange Commission (SEC) Advisory Committee on Improvements to Financial Reporting [ACIFR] recommended mandatory phased-in adoption of XBRL tagging for SEC filings (ACIFR 2008), meaning all companies should adopt XBRL (Barlas 2008). April of 2009 brought an SEC mandate that requires all firms that are publicly traded on U.S. stock exchanges must file XBRL tagged financial statements to the SEC and publish these statements on their corporate websites by 2012 (SEC 2009). Other regulatory agencies, such as the U.S. Federal Deposit Insurance Corporation (FDIC, 2004) and the Australian Prudential Regulation Authority are also involved in efforts to use XBRL for regulatory reporting (Fahy et al. 2003, Kroener 2003, Hannon 2002). A survey found that two-thirds of accounting software vendors have released or are in the process of releasing XBRL-enabled products (XBRL 2003).

Along with all these mandates and calls for the use of XBRL, even more numerous predictions have appeared of the radical impacts its adoption will have on business and the accounting profession (Cohen 2005, Trites 2004, Wagenhofer 2003, Coffin 2001a \& 2001b). However, some have suggested that interest in this type of technology is low (Xiao et al. 2002) and others have cautioned against overstatement and over hype by XBRL enthusiasts (Locke and Lowe 2007). Unfortunately, these predictions have been supported by little research investigating the probability of future XBRL impacts. Bonson et al. (2009), Pinsker (2008), and Troshani and Rao (2007) have studied XBRL adoption generally, and Doolin and Troshani (2007) have studied the lack of widespread XBRL adoption in Australia. While researchers have begun to investigate some specific XBRL impacts (Hodge et al. 2004, Pinsker 2003, Bovee et al. 2002, Bonson 2001), much more information is needed about potential and actual impacts. 
Abdolmohammadi et al. (2002) suggest experimental studies to address XBRL's impact on variables such as ease of use, efficiency and effectiveness of financial reporting, and stakeholder trust enhancement. Because XBRL is expected by many to become the standard for financial reporting (The Futurist 2003), the assessment of the long-term effects of XBRL is an important research question. This project adds to the extant research by presenting the results of a future forecasting Delphi study that addresses the impacts of XBRL in the second decade of the new millennium. The Delphi survey method (Linstone 1985) is often used to gain consensus among experts regarding the probabilities of future trends and impacts (Holstrum et al. 1986).

The next section describes a framework of propositions based on the current XBRL literature. The third section elaborates the research method, followed in the next section by the results of the study. Finally, conclusions are drawn.

\section{A FRAMEWORK OF PROPOSITIONS}

What will be the future impacts of XBRL? Extant research on XBRL was collected and analyzed for the purpose of setting up a framework of users and the potential benefits of XBRL. The authors examined the literature to identify discussions and assertions about XBRL's potential impacts, both positive and negative. Many articles described a wide variety of potential impacts. The impacts were all examined and categorized. They are described in the following section. The potential impacts of XBRL that were considered to be of greatest interest to investors, corporations, and regulatory bodies were divided into a number of categories for the current study: (1) corporate and compliance, (2) financial reporting, (3) users of financial reports, (4) and auditing.

\section{Corporate and Compliance Impacts}

Gathering and disseminating data for business decisions typically requires a considerable investment of time and effort. The associated processes are often duplicated in order to generate financial reports, publish information on the corporate website, provide necessary data to decision makers, etc. (Deshmukh 2004). XBRL provides a means to potentially eliminate the repetitiveness of the data gathering processes (Shuetrim and Somerville 2004, DiPiazza and Eccles 2002). Through the use of XBRL enabled software, decision makers can receive the desired information directly into the analysis software. By eliminating the need to use information intermediaries, visit corporate websites, or leaf through paper reports, the decision making process will become more efficient and flexible (Rezaee and Turner 2002). As these benefits are realized, the effectiveness of the decision making process is increased (DiPiazza and 
Eccles 2002). Additionally, XBRL can be used without scrapping legacy systems (Lin et al. 2005).

Beyond the benefits realized in the decision making process, corporations will also benefit from easier regulatory compliance. As part of its stated goal, XBRL International is striving for XBRL to provide the global business community with a tool for annual and quarterly regulatory filings (Callaghan et al. 2002). The ability to efficiently gather and disseminate data will ease compliance with the SEC disclosure requirements for 10-K and 10-Q filings (Stantial 2007), with the disclosure requirements of Regulation FD ${ }^{1}$ (Fair Disclosure), and with other regulatory bodies such as OSHA and the FCC (Alles et al. 2002). The ability to publish information once and reuse it many times (DiPiazza and Eccles 2002) will make the process of regulatory compliance more efficient and less costly (Bonson et al. 2009; Pinsker and Shaomin 2008).

\section{Financial Reporting}

The potential benefits of improved efficiencies are realized in regards to the financial reporting process as well. The tagging (in accordance with a set taxonomy) of every piece of information relevant to financial reporting will result in a stable and consistent system that make the collection of data for and the preparation of financial reports efficient and effective (Pinsker and Shaomin 2008; Pinsker et al. 2005; Bovee et al. 2002). This is made possible as vendors of accounting software are incorporating XBRL into their products, thus making the creation of a wide variety of financial reports automated (Branson 2002). The tagging and resulting automation of report generation will make the creation of misleading financial statements by management more difficult (Rezaee and Turner 2002; DiPiazza and Eccles 2002), improving transparency (Hodge et al. 2004).

The issue with lack of comparability between firms when their financial statements are presented in accordance with different standards will become moot. While XBRL is not likely to eliminate differences in GAAP interpretation (Teixeira 2005), it will make the generation of reports under different standards possible through the tagging of every event. To some extent, it may result in the standardization of information content (Wagenhofer 2003). The need for an extensive and expensive conversion project to keep multiple sets of books will not be necessary. Firms will be able to easily access the necessary data to compile reports under different sets of standards (Coffin 2001b).

\footnotetext{
${ }^{1}$ Regulation FD requires that when a firm discloses nonpublic information to certain persons (e.g., institutional investors) that they disclose this information publicly (SEC 2000).
} 
The efficiencies in the financial reporting process (e.g., data collection and report generation) will also be realized in the audit. The audit process has evolved from the manual audit to a computer-based audit and through the advent of XBRL is poised to evolve into the continuous audit (Rezaee et al. 2002, McGuire et al. 2006). Some even espouse a more extreme view that continuous auditing could lead to continuous reporting which could supplement and then replace traditionally annual audit reports (Alles et al. 2002).

Combined with the gain in efficiency in the audit processes, XBRL stands to improve the efficiency of the entire financial reporting process, which will lead to decreased audit costs (Bonson et al. 2009; Rezaee et al. 2002) and reductions in the cost of creation (Rezaee and Turner 2002) and dissemination of the financial reports (Ashbaugh et al. 1999). The improvements in efficiency will also release personnel and computer resources from the financial reporting process that can be used in other areas of the firm (Bonson et al. 2009; Pinsker and Shaomin, 2008).

\section{Users of Financial Reports}

The firms generating the financial information are not the only beneficiaries of XBRL technology. The users of the financial information will benefit as well. Traditionally, users of financial information must pore through paper-based financial statements or rely on information intermediaries to provide access to the data. Costs, inefficiencies, and potential problems are inherent in these methods.

Consuming information is a costly process. Costs arise in both collecting the information and in converting it into a useful format (DiPiazza and Eccles 2002). These costs are the result of time spent sifting through the traditional financial report or through a firm's website to get the necessary data (Ashbaugh et al. 1999). Once the data is collected, it then must be converted and/or manually keyed into analytical software. XBRL and XBRL-enabled software allow users to receive the desired information directly into their analytic software, thus decreasing the costs and improving the accuracy of data collection and conversion (DiPiazza and Eccles 2002).

Data collection is also performed by intermediaries, such as EDGAR Online (2003) and Hoover's Online. XBRL and XBRL-enabled software, such as intelligent Internet agents (Callaghan et al. 2002), improve the accessibility of financial information (Baldwin and Williams 1999, Fox et al. 2002, Lester 2007). Improved accessibility will reduce, if not remove, the need for reliance upon these intermediaries for a convenient source of information (Coffin 2001b). While the intermediaries may not cease to exist, 
they will need to retool their operations in order to remain viable. This retooling may involve tagging of historical data and/or assisting firms in the adoption of XBRL.

Applications may use XBRL to automate and integrate changing financial information from multiple sources (Marshall et al. 2010; Burnett et al. 2006; Bovee et al. 2005; Bonson 2001). XBRL will provide the ability to access data electronically and continuously will improve the timeliness of the financial information (Bovee et al. 2002; Bonson 2001). As the timeliness improves, the efficiency of the decision making process is improved (DiPiazza and Eccles 2002).

Another problem associated with current reporting of financial data is the understandability of the information. Data intermediaries attempt to alleviate this problem by normalizing the data into standardized formats and categories. This data cleaning procedure distorts the information and hides the subtleties necessary for understanding and analysis (Debreceny and Gray 2001), thus making it potentially inaccurate and/or deceptive and less valuable. XBRL tagging according to set taxonomies is performed by the creators of the information, thus eliminating the need for normalization (DiPiazza and Eccles 2002).

While normalization does have its problems, data that is cross-sectionally comparable is necessary. The use of standardized XBRL taxonomies makes cross-sectional comparisons between companies in a specific industry possible (Bonson et al.2009; Bovee et al. 2002, Callaghan et al. 2002, Debreceny and Gray 2001). While this benefit is possible within an industry, the degree of specialization between industries makes the use of one taxonomy virtually impossible. Many different taxonomies are being developed for specific industries, which will not benefit comparisons between industries (Rezaee and Turner 2002).

Improved efficiency and accessibility to financial data will lead to analysts being able to incorporate more data into their analysis and analyzing it with greater accuracy (Marshall et al.2010; Bonson et al.2009; Rezaee and Turner 2002; Bonson 2001), thus improving their investment decisions (Bovee et al. 2002). This will lead to analysts being able to follow more companies, consequently benefiting the investors and the companies (DiPiazza and Eccles 2002). One potential problem with the increased accessibility of information is that investors may be relying on un-audited information (Ashbaugh et al. 1999), which will not disappear as a result of XBRL, because much information on corporate websites is not audited and, therefore, would not be audited during a continuous audit (e.g., much of the corporate governance voluntary disclosures). 


\section{Audit}

As mentioned previously, XBRL facilitates the continuous audit and reduces audit costs (Pinsker 2003, Rezaee et al. 2002). Electronic real-time-reporting and the continuous audit necessitate the need for increased internal controls (Boritz and No 2005 $\&$ 2004). These controls are necessary to ensure the validity and reliability of the information (Rezaee et al. 2002). XBRL tagging must be properly performed in accordance with the given taxonomies and the reports must be filed in accordance with the proper accounting standards. Clearly, the effectiveness of internal control over the validity and completeness of financial data will determine the competence of such electronic evidence (AICPA 1997, Rezaee et al. 2002). Table 1 lists all of the previously discussed propositions.

\section{Corporation and Compliance}

1. XBRL increases the efficiency of business decision making.

2. XBRL increases the effectiveness of management decision making.

3. XBRL allows for easier regulatory compliance.

4. XBRL makes it more difficult for management to issue misleading financial statements.

\section{Financial Reporting}

5. XBRL increases the efficiency of the financial reporting process.

6. XBRL decreases the occurrence of errors in financial reports.

7. XBRL reduces the cost of generating financial reports.

8. XBRL facilitates continuous reporting.

9. XBRL enhances the availability of financial reports.

10. XBRL eliminates the need for convergence of generally accepted accounting principles.

\section{Users of Financial Reports}

11. XBRL provides more accessible financial reports to users.

12. XBRL provides more understandable financial reports for users.

13. XBRL enables more thorough research by analysts because of access to more detailed financial data.

14. XBRL increases the use of un-audited information by investors.

15. XBRL decreases reliance on third-party information providers by users of financial reports.

16. XBRL decreases the ability of financial analysts to perform cross-sectional analysis between industries.

17. XBRL increases the ability of financial analysts to perform cross-sectional analysis within industries.

18. XBRL decreases the cost of financial analysis performed by users of financial reports.

19. XBRL allows more efficient investment decisions by users of financial reports.

\section{Audit}

20. XBRL facilitates continuous auditing.

21. XBRL reduces financial statement audit costs.

22. XBRL leads to improvement in internal controls.

Table 1. Framework of Propositions 


\section{RESEARCH METHOD}

This section includes a brief discussion of the Delphi survey method and the rationale for the make-up of the panel of experts that participated in the survey.

\section{Delphi Survey Method}

The proposed impacts of XBRL are examined using the Delphi technique. The Delphi survey method (Linstone 1985) is often used to gain consensus among experts regarding the probabilities of future trends and impacts (Holstrum et al. 1986). A problem with studies that use conventional survey methods to predict the impact of future events is a lack of interaction among participants. This problem is overcome through the use of panel discussions; however, strong personalities can dominate these discussions (Linstone 1985), leading to conclusions that are biased toward the view of the dominant personality. The Delphi technique is effective in eliminating the impact of strong personalities and allowing consensus to be reached by the expert panel. The Delphi method has been used in various business disciplines including accounting (Garsombke and Cerrulo 1984), auditing (Baldwin-Morgan 1993, Ramamoorti et al. 1999), banking (Bradley and Stewart 2002), international business (Czinkota and Ronkainen 1997), and business process engineering (Zarei 2001). In information systems research, the use of the Delphi technique has been ubiquitous for decades (for example, Addison 2003, Mursu et al. 2003, Bourqe et al. 2002, McCoy 2001, Holsapple and Joshi 2001, Schmidt et al. 2001, Hayne and Pollard 2000, Keil et al. 1998, Brancheau and Wetherbe 1987).

The Delphi technique uses three survey rounds in which members of the panel of experts provide a probability of occurrence of the given event and their rationale behind their prediction. The current study, as well as many prior Delphi studies, utilizes extant research and interviews with domain experts to determine the events/impacts that formulate the propositions that are included in all three rounds of the study in order to have quantitative data in all survey rounds (Hasson et al.2000).

During rounds two and three the participants are given, for each proposition ${ }^{2}$ that did not reach consensus in the prior round, their prediction/probability ${ }^{3}$ from the previous round, the average probability of the group, the inter-quartile range of probabilities, and

\footnotetext{
${ }^{2}$ The propositions were randomly re-ordered for each round of the survey.

${ }^{3}$ For clarity and presentation purposes, subjects' responses were converted into whole numbers (.99 becomes 99 , etc.). A probability of 0.50 represents a neutral position that the impact could go in either direction.
} 
the rationales (anonymously). The provision of the mean responses and rationales is in effect a pseudo discussion and allows for adjustments to individual probabilities during rounds two and three (Cundiff 1985). Linstone and Turoff (1975) suggest that three rounds provide an optimal number of repitions of the process. At the end of three rounds, the panel will have reached consensus or will have shown that they are not likely to do so (Baldwin-Morgan 1993). For a thorough explanation of the Delphi technique see Linstone and Turoff (1975).

Panel members participated via a web-based survey in which they were asked to evaluate 26 possible impacts of XBRL and to provide a probability for the occurrence of each proposition and their rationale for their decisions. The participants were allowed to complete the survey at their leisure with the stipulation that each round be completed at one sitting ${ }^{4}$. The participants received an e-mail containing a request for participation in the current round and a link to the website for the survey.

\section{Panel of Experts}

In order to insure that the panel members have the knowledge of XBRL that would classify them as experts, potential members of the panel were selected from accounting and information systems academicians who teach and do research on XBRL, financial reporting practitioners working with XBRL, and those that are very involved with XBRL International (www.xbrl.org) as well as the firm, company and agency liaisons who work with XBRL International in the development of the XBRL taxonomy and its incorporation in software and in regulatory practices. Both academicians and practitioners were included to ensure that a wide spectrum of viewpoints is included in the panel. While the makeup of the panel may seem to bias the study toward an overly optimistic view of the impacts of XBRL, people who are involved in the present events that are shaping the future are the most knowledgeable about a given future event and interviews with them can lead to the establishment of the likelihood of impacts if the technological trends continue (Baldwin-Morgan 1993).

\section{RESULTS}

Round one of the survey consisted of 71 potential panel members being recruited via e-mail yielded 12 usable responses ${ }^{5}$, a response rate of approximately 17 percent. Rounds

\footnotetext{
${ }^{4}$ This was a limitation of the survey technology, not a requirement of the Delphi technique.

${ }^{5}$ A usable response is a response that includes a probability that fit within a range of 0-99 (scaled) and that the rationale (if provided) fit with the given proposition.
} 
two and three resulted in 9 usable responses ( $75 \%$ of the 12 subjects originally agreeing to participate completed the entire survey), which is an acceptable maintenance rate for a Delphi study to be considered as valid (Hasson et al. 2000).

While a larger number of participants were hoped for, the minimum recommended Delphi panel size is seven (Dalkey and Helmer 1963) 6 . Of the nine participants completing the survey, four are accounting and information systems academicians researching XBRL, five are involved in the development and use of XBRL and members of XBRL International, and two have sponsored student teams in XBRL competitions. All have either published research on XBRL or are members of XBRL International (some are both). The panelists are currently employed in the USA, Canada, Singapore and Australia. As previously discussed, the make-up of the panel provides for a breadth of viewpoints that adds to the validity of the current study.

Final results for all statements are given in Table 2 for the entire panel. When predictions on any proposition reached consensus, that proposition was removed from the following round. According to Linstone (1985), in most Delphi investigations, consensus is assumed to have been achieved when a certain percentage of responses fall within a prescribed range, such as when the inter-quartile range (IQR) is no larger than 20 percent of the scale. Using this rule of thumb, the expert panelists reached consensus on 14 of the 26 propositions by the end of round three.

\section{Most Likely Impacts}

The mean response of the Delphi panel was above 75 for eight propositions. The most likely impacts include three concerning financial reporting (P5, P8, and P9), two relating to users of financial reports (P11 and P19), two addressing corporate impacts (P1 and P3), and one regarding auditing (P20). These results are addressed as each group of propositions is discussed.

\section{Least Likely Impacts}

Only one proposition, P10, concerning the need for GAAP convergence, received a mean panel response below 25 . This proposition was rated very unlikely, with a mean response of 10. Only two panelists rated this proposition higher than 10 in probability. In addition to meeting Linstone's rule of thumb for consensus ( $\mathrm{IQR} \leq 20 \%$ of scale), this proposition's predictions yielded the smallest standard deviation. The maximum response

\footnotetext{
${ }^{6}$ Extant research has used samples from five to in excess of 40 .
} 
to this statement was 30 .

The rationales for $\mathrm{P} 10$ indicate that no individual panelist believes that $\mathrm{XBRL}$ is likely to eliminate the need for convergence of generally accepted accounting principles. Rather, panelists suggest that the need for convergence arises from greater economic and political issues than from technology. This is not surprising, given current developments in International Financial Accounting Standards. While XBRL can enhance the value and usability of existing standards, it will not replace them nor will it eliminate the need for standards and both translation and convergence of disparate GAAP.

\begin{tabular}{|c|c|c|c|c|c|c|c|}
\hline & & & \multirow{2}{*}{$\begin{array}{l}\text { Standard } \\
\text { Deviation }\end{array}$} & & & \multirow{2}{*}{$\begin{array}{l}\text { Response } \\
\text { (see note) } \\
\end{array}$} & \\
\hline Proposition & Category & Mean & & Min & Max & & $\begin{array}{c}\text { Width of Inter-Quartile } \\
\text { Range }<=\mathbf{2 0}\end{array}$ \\
\hline 1 & Corporation & 76.67 & 12.99 & 60 & 100 & very likely & yes \\
\hline 2 & Corporation & 47.22 & 21.08 & 10 & 80 & slightly unlikely & \\
\hline 3 & Corporation & 84.58 & 22.20 & 20 & 100 & very likely & yes \\
\hline 4 & Corporation & 43.56 & 30.00 & 10 & 90 & slightly unlikely & \\
\hline 5 & Reporting & 79.58 & 23.98 & 20 & 100 & very likely & \\
\hline 6 & Reporting & 63.67 & 23.26 & 25 & 100 & likely & \\
\hline 7 & Reporting & 53.33 & 25.37 & 20 & 90 & slightly likely & \\
\hline 8 & Reporting & 81.44 & 14.71 & 50 & 100 & very likely & yes \\
\hline 9 & Reporting & 80.25 & 13.81 & 50 & 98 & very likely & yes \\
\hline 10 & Reporting & 10.00 & 10.90 & 0 & 30 & very unlikely & yes \\
\hline 11 & Users & 85.42 & 12.52 & 60 & 100 & very likely & yes \\
\hline 12 & Users & 45.56 & 25.67 & 0 & 80 & slightly unlikely & \\
\hline 13 & Users & 59.89 & 22.56 & 25 & 95 & slightly likely & \\
\hline 14 & Users & 61.11 & 14.53 & 30 & 80 & likely & yes \\
\hline 15 & Users & 52.78 & 21.52 & 10 & 95 & slightly likely & yes \\
\hline 16 & Users & 28.33 & 25.12 & 0 & 85 & unlikely & \\
\hline 17 & Users & 74.44 & 15.90 & 50 & 100 & likely & yes \\
\hline 18 & Users & 63.89 & 18.16 & 30 & 90 & likely & \\
\hline 19 & Users & 82.92 & 21.58 & 20 & 100 & very likely & yes \\
\hline 20 & Audit & 76.11 & 14.31 & 50 & 100 & very likely & yes \\
\hline 21 & Audit & 42.78 & 16.98 & 15 & 65 & slightly unlikely & \\
\hline 22 & Audit & 49.44 & 23.24 & 10 & 80 & slightly unlikely & \\
\hline
\end{tabular}

Table 2. Descriptive Statistics for Round Three 


\section{Corporate Impacts}

Among the corporate impacts propositions, P3 (XBRL allows for easier regulatory compliance) was the most likely. This proposition was the second most likely among all propositions in the study, with a mean probability of 84.58 , rating it as very likely. According to Linstone's rule of thumb (IQR $\leq 20 \%$ of scale), consensus was reached in the first Delphi round. Only one subject $(n=12)$ gave a prediction below 70 . The rationales explain that in some countries XBRL is already being used for regulatory compliance (e.g. Australian Prudential Regulatory Authority and the Australian Bureau of Statistics) in others its use is being planned in the near future (e.g. FDIC). Others suggest that this is the entire point of developing XBRL in the first place. XBRL will help make preparation of reports easier, which will promote more timely and more accurate regulatory reporting and easier methods to exchange information.

Proposition 1 (XBRL increases the efficiency of business decision making) was rated as very likely (mean $=76.67$ ) and consensus was achieved. No panel gave this proposition a probability less than 60 . According to the rationales, the speed of decision making, especially routine decisions, should be increased by the use of XBRL. In addition, XBRL documents can be easily transformed into other formats providing better access to data needed for decisions. However, one panelist suggests that the initial learning curve may slow down efficiency in the short-term before real benefits emerge.

\section{Financial Reporting}

Of the six propositions addressing the financial reporting, three resulted in consensus according to Linstone's rule of thumb (IQR $\leq 20 \%$ of scale): P8, P9, and P10. Proposition 10 (XBRL eliminates the need for convergence of generally accepted accounting principles) was, in fact, the least likely impact in the entire study. It was discussed above.

Proposition 8 (XBRL facilitates continuous reporting) was also predicted to be very likely (mean $=81.44)$. No panelist rated this proposition below 50 , and only one panelist rated it less than 75. Rationales indicate that XBRL information can make its way to the Internet more quickly than non-XBRL information. Using XBRL, a company can easily generate, publish, and exchange XBRL-coded financial information - this is particularly true for internal use. However, large businesses may be more likely to achieve continuous reporting with XBRL due to economies of scale and superior technology integration. And, of course, the issue of continuous reporting of un-audited information must be considered.

Proposition 9 (XBRL enhances the availability of financial reports) was predicted to 
be very likely (mean $=80.25$ ). This proposition achieved consensus early, in round one. No panelist rated this proposition below 50. Panelists explained that XBRL will allow for more easily available repositories of company financials whose availability is more timely. XBRL will allow for more access over the Internet as well as easier exchange of financial data.

\section{Users of Financial Reports}

Of the nine propositions concerning financial statement users, five achieved consensus (P11, P14, P15, P17 and P19) according to Linstone's rule of thumb (IQR $\leq 20 \%$ of scale). The remaining four did not achieve consensus and resulted in wide response ranges between 60 and 85). The discussion below focuses on the consensus propositions.

Proposition 11 (XBRL provides more accessible financial reports to users) was rated as very likely and, in fact, was the most likely of all the impacts studied (mean $=85.42$ ). This proposition achieved consensus in the first round of the study. No panelist rated this proposition lower than 60 . Rationales reveal that panelist expect the interchangeability of XBRL to facilitate access by users, including to SEC reports. The standardization will, by definition, make this information more accessible. Some panelists believe this is only true if the SEC mandates XBRL reporting.

Proposition 14 (XBRL increases the use of un-audited information by investors) was rated as likely (mean $=74.44$ ). While the range of responses was fairly wide, only one panelist made a prediction less than 50, resulting in a narrow inter-quartile range $(\mathrm{IQR}=15)$. While many panelists believe XBRL will result in more information being made available, they do not necessarily conclude that this information will necessarily be un-audited. The high prediction on P24 (XBRL facilitates continuous auditing) supports this thinking and is discussed in the next section. Panelist rationales suggest that while users are likely to use whatever information is available, and some of that may be unaudited, they will continue to discount the un-audited information when compared to the audited.

Proposition 15 (XBRL decreases reliance on third-party information providers by users of financial reports) was rated as slightly likely (mean $=52.78$ ). While two responses were extreme outliers (one of each end of the scale) all other responses were near the neutral middle of the scale. The uncertainty of this proposition shows in the rationales, since third-party providers generally provide easier access. However, XBRL may be the great leveler in making the financial analysis task easier to do without the third party. Aggressive aggregators will likely innovate new ways to add value. However, 
less savvy third-party providers could likely fall by the wayside.

Proposition 17 (XBRL increases the ability of financial analysts to perform crosssectional analysis within industries) achieved consensus in the second round and was rated as likely (mean $=74.44$ ). Only one panelist rated this proposition below $70(50)$. Rationales suggest that wide adoption of XBRL will certainly increase this ability for analysts, particularly because industry information will be tagged in the same way. Standardization, in general, should help. However, some taxonomies could take longer than 2010 to finalize and begin use.

Proposition 19 (XBRL allows more efficient investment decisions by users of financial reports) was also rated as very likely (mean $=82.92$ ) and was the fourth most likely proposition in the study. This proposition achieved consensus in the first round of the study. Only one panelist rated this proposition lower than 75, an extreme outlier of 20. Rationales note that XBRL data will be easier to manipulate in custom designed analytical tools, will allow better comparisons than non-XBRL data, will facilitate improved multiple company analysis, and will make decisions more efficient primarily due to increased timeliness.

\section{Audit Impacts}

Only one of the audit impacts achieved consensus according to Linstone's rule of thumb (IQR $\leq 20 \%$ of scale), P20 (XBRL facilitates continuous auditing). This proposition was rated as very likely with a mean response of 76.11. Not one panelist rated this proposition's likelihood below 50. Rationales predict that with XBRL, intelligent agents can be created to monitor performance and compliance. The tools will certainly be likely to support continuous auditing, however two panelists questioned whether business practices will change to utilize this opportunity.

\section{CONCLUSION AND FUTURE RESEARCH}

According to The Futurist, XBRL is one of seven cutting-edge technologies that will have a big impact on business and revolutionize corporate performance (The Futurist 2003). Though earlier articles (Baldwin et al. 2006, Debreceny and Gray 2001) have noted the rich research opportunities XBRL provides -- in such areas as taxonomies, databases, assurance, intelligent agents, interfaces, standards development and others -researchers have only recently begun to address any aspect of XBRL use and adoption (Bonson et al. 2009, Pinsker and Shaomin 2008, and Troshani and Rao 2007, Doolin and Troshani 2007). 
This project adds to the extant research by presenting the results of a future forecasting Delphi study that addresses the impacts of XBRL in the second decade of the new millennium. This study truly provides a window into the future of XBRL and its effect on accountants and auditors, as well as corporations, regulators and users of financial reports.

The Delphi panel suggests that XBRL is very likely to have an impact on corporations, financial reporting, users of financial reports and auditing. The Delphi panel predicts that XBRL is very likely, by the second decade of the millennium:

- to provide users with more accessible financial reports;

- to make financial reports more accessible to users;

- to allow easier regulatory compliance;

- to allow more efficient investment decisions;

- to facilitate continuous reporting and continuous auditing;

- to enhance availability of financial reports; and

- to increase the efficiency of business decision making.

In contrast, panelists uniformly agree that XBRL is very unlikely to eliminate the need for convergence of generally accepted accounting principles. Most panelist's rationales were tempered with some skepticism regarding the near miraculous impacts that some XBRL adherents and accounting futurists have proposed. The fact that the panelists do not predict that XBRL will promote understandability or reduce financial statement audit costs suggests that XBRL is not the be-all and end-all technology leap that some would have us believe.

As accounting software packages continue to incorporate XBRL tags, its use will become easier. As more regulatory agencies mandate the use of XBRL in filings, its use may become ubiquitous. The primary contribution of this research is to provide evidence as to the future of XBRL's use in accounting, corporate reporting and regulation. This study provides support for some of the common concepts of XBRL impacts, but tempers expectations on other impacts. From this study, a framework (shown in Table 3) can begin to develop that will include the more likely impacts and exclude the least likely impacts. 


\section{Corporation and Compliance}

- $\quad$ XBRL increases the efficiency of business decision making.

- XBRL allows for easier regulatory compliance.

Financial Reporting

- XBRL facilitates continuous reporting.

- XBRL enhances the availability of financial reports.

- XBRL eliminates the need for convergence of generally accepted accounting principles.

Users of Financial Reports

- $\quad$ XBRL provides more accessible financial reports to users.

- XBRL increases the use of un-audited information by investors.

- XBRL increases the ability of financial analysts to perform cross-sectional analysis within industries.

- $\quad$ XBRL allows more efficient investment decisions by users of financial reports.

Audit

- $\quad$ XBRL facilitates continuous auditing.

Table 3. Framework of Likely XBRL Impacts

Future research should first focus on the impacts identified as likely or very likely, especially those on which the Delphi panel reached consensus. As XBRL continues to be developed and more regulatory agencies mandate its use, studies should be undertaken that address impacts in the early development areas and the countries whose agencies are early adopters. Studies of the use of XBRL for reporting to the SEC (e.g., Bonson et al. 2009), the Australian Prudential Regulatory Agency, and the Australian Bureau of Statistics will provide further information on XBRL impacts that may be relevant to other agency adoptions and in other geographical locations.

Future studies may also focus on XBRL implementation in a single industry or XBRL use related to one widely used accounting package. Important questions include: How does XBRL implementation affect industry comparability? How does the integration of XBRL into accounting software impact the quality and efficiency of the financial information of adopting companies?

\section{REFERENCES}

ABDOLMOHAMMADI, M.; HARRIS, J.; SMITH, K. (2002): “Government financial reporting on the Internet: The potential revolutionary effects of XBRL", The Journal of Government Financial Management, vol. 51, n. 2: 24-31.

ADDISON, T. (2003): “E-commerce project development risks: Evidence from a Delphi 
survey", International Journal of Information Management, vol. 23, n. 1: 25-36. http://dx. doi.org/10.1016/S0268-4012(02)00066-X

ADVISORY COMMITTEE ON IMPROVEMENTS TO FINANCIAL REPORTING (SEC) (2008): "Progress Report version 2". (Accessed February 11, 2008). Available online: http://www.sec.gov/about/offices/oca/acifr/acifr-dpr-021108-v2

ALLES, M. G.; KOGAN, A.; VASARHELYI, M. A. (2002): "Feasibility and Economics of Continuous Assurance", Auditing: A Journal of Practice \& Theory, vol. 21, n. 1: 125138.

AMERICAN INSTITUTE OF CERTIFIED PUBLIC ACCOUNTANTS. (2006): “Top Ten Technologies", http://infotech.aicpa.org/Resources/Top++10+Technologies/

AMERICAN INSTITUTE OF CERTIFIED PUBLIC ACCOUNTANTS. (1997): “The Information Technology Age: Evidential Matter in Electronic Environment", AICPA, New York.

AMERICAN INSTITUTE OF CERTIFIED PUBLIC ACCOUNTANTS. (1994): "Improving Business Reporting - a customer focus. Report of the special committee on financial reporting", AICPA, New York.

ASHBAUGH, H.; JOHNSTONE, K. M.; WARFIELD, T. D. (1999): "Corporate Reporting on the Internet”, Accounting Horizons, vol. 13, n. 3: 241-257. http://dx.doi.org/ 10.2308/acch.1999.13.3.241

BALDWIN, A. A.; BROWN, C. E.; TRINKLE, B. S. (2006): "XBRL: An impacts framework and research challenge", Journal of Emerging Technologies in Accounting, vol. 3: 97-116. http://dx.doi.org/10.2308/jeta.2006.3.1.97

BALDWIN, A. A.; WILIAMS, S. L. M. (1999): "The Future of Intelligent Internet Agents in European Financial Reporting", European Accounting Review, vol. 8, n. 2: 303319. http://dx.doi.org/10.1080/096381899336050

BALDWIN-MORGAN, A. A. (1993): "The impact of expert system audit tools on auditing firms in the year 2001: A Delphi investigation”, Journal of Information Systems, vol. 7 , n. 1: 16-34.

BARLAS, S. (2008): "CIFiR nacks mandatory XBRL, tougher restatement criteria", Strategic Finance, vol. 89, n. 9: 61-62.

BONSON, E. (2001): "The role of XBRL in Europe", The International Journal of Digital Accounting Research, vol. 1, n. 2: 101-110. http://dx.doi.org/10.4192/1577-8517-v1_5 
BONSON, E.; CORTIJO, V.; ESCOBAR, T. (2009): “A Delphi investigation to explain the voluntary adoption of XBRL", The International Journal of Digital Accounting Research, vol. 9: 193-205. http://dx.doi.org/10.4192/1577-8517-v9_7

BORITZ, J. E.; NO, W. G. (2005): "Security in XML-based financial reporting serices on the Internet", Journal of Accounting \& Public Policy, vol. 24, n. 1: 11-35. http://dx.doi.or $\mathrm{g} / 10.1016 / \mathrm{j} . j \mathrm{jaccpubpol} .2004 .12 .002$

BORITZ, J. E.; NO, W. G. (2004): "Assurance reporting for XML-based information services: XARL”, Canadian Accounting Perspectives, vol. 3, n. 2: 207-233. http://dx.doi. org/10.1506/V8D9-QTUN-HDU1-93RB

BOURQE, P.; DUPUIS, R.; ABRAN, A.; MOORE, J. W. (2002): "Fundamental principles of software engineering - A journey", The Journal of Systems and Software, vol. 62, no. 1: 59-71. http://dx.doi.org/10.1016/S0164-1212(01)00136-4

BOVEE, M.; KOGAN, A.; NELSON, K.; SRIVASTAVA, R.; VASARHELYI, M. A. (2005): "Financial Reporting and Auditing Agent with Net Knowledge (FRAANK) and eXtensible Business Reporting Language (XBRL)". Journal of Information Systems, vol. 19, n. 1: 19-41. http://dx.doi.org/10.2308/jis.2005.19.1.19

BOVEE, M.; ETTREDGE, M. L.; SRIVASTAVA, R. P.; VASARHELYI, M. A. (2002): "Does the year 2000 XBRL taxonomy accommodate current business financial-reporting practice?", Journal of Information Systems, vol. 16, n. 2: 165-182. http://dx.doi.org/10.23 08/jis.2002.16.2.165

BRADLEY, L.; STEWART, K. (2002): "A Delphi study of the drivers and inhibitors of Internet banking", The International Journal of Bank Marketing, vol. 20, n. 6: 250-261. http://dx.doi.org/10.1108/02652320210446715

BRANCHEAU, J. C.; WETHERBE, J. C. (1987): "Key issues in information systems management”, MIS Quarterly, vol. 11, n. 1: 22-46. http://dx.doi.org/10.2307/248822

BRANSON, M. (2002): “Using XBRL for data reporting”, Statistical Journal of the United Nations, vol. 19, n. 3: 201-204.

BURNETT, R. D.; FRIEDMAN, M.; MURTHY, U. (2006): "Financial reports: Why you need XBRL", Journal of Corporate Accounting and Finance, vol. 17, n. 5: 33-40. http://d X.doi.org/10.1002/jcaf.20229

CALlAGHAN, J. H.; SAVAGE, A.; SUGUMARAN, V. (2002): “Augmenting XBRL using UML: Improving financial analysis", The Review of Business Information Systems, 
vol. 6, n. 4: 27-33.

CANADIAN INSTITUTE OF CHARTERED ACCOUNTANTS (1999): "The impact of technology on financial and business reporting - 1999 - executive summary", http://bit.ly/dQtAa6

COFFIN, Z. (2001a): "The top 10 effects of XBRL", Strategic Finance, vol. 82, n. 12: 64-67.

COFFIN, Z. (2001b): "Top Ten Effects of XBRL: The Future of Internet Reporting". In Introducing XBRL“ (Chapter 17): Prentice-Hall: New York. Available on-line at: http://www.xbrl.org/BriefingRoom.htm.

COHEN, E. E. (2005): "Compromise or customize: XBRL's paradoxical power", Canadian Accounting Perspectives vol. 3, n. 2: 187-206. http://dx.doi.org/10.1506/YAHN -CAE8-5CWQ-H4TE

CUNDIFF, W. E. (1985): "Interactive software for the capture, management, and analysis of data in Delphi inquiries" Technological Forecasting and Social Change, vol. 28, n. 2: 173-185. http://dx.doi.org/10.1016/0040-1625(85)90013-7

CZINKOTA, M. R.; RONKAINEN, I. A. (1997): "International business and trade in the next decade: Report from a Delphi study", Journal of International Business Studies, vol. 28, n. 4: 827-844. http://dx.doi.org/10.1057/palgrave.jibs.8490121

DALKEY, N.; HELMER, O. (1963): "An experimental application of the Delphi method to the use of experts", Management Science, vol. 9, n. 3: 458-467. http://dx.doi.org/10.12 $\underline{87 / m n s c .9 .3 .458}$

DEBRECENY, R.; GRAY, G. L. (2001): "The production and use of semantically rich accounting reports on the Internet: XML and XBRL", International Journal of Accounting Information Systems, vol. 2, n. 1: 47-74. http://dx.doi.org/10.1016/S1467$\underline{0895(00) 00012-9}$

DESHMUKH, A. (2004): "XBRL", Communications of the Association for Information Systems, vol. 13, n. 16: 196-219.

DIPIAZZA, S. A. Jr.; ECCLES, R. G. (2002): "Building public trust", The Internet. John Wiley \& Sons, New Jersey.

DOOLIN, B.; TROSHANI, I. (2007): "Organizational adoption of XBRL", Electronic Markets, vol. 17, n. 3: 199-209. http://dx.doi.org/10.1080/10196780701503195 
EDGAR ONLINE (2003): "Microsoft to team with EDGAR Online to facilitate analysis on the desktop", http://www.edgar-online.com/investor/news/110503.asp

ELYSÉE, M.; SHUETRIM, G.; TURNER, J. (2004): “A common language for a common goal”, Frontiers in Finance, vol. June: 44-47. http://bit.ly/f2lq4r

ETTREDGE, M.; RICHARDSON, V. J.; SCHOLZ, S. (2002): "Timely financial reporting at corporate websites?", Communications of the ACM, vol. 45, n. 6: 67-71. http://dx.doi.org/10.1145/508448.508450

FAHY, M.; FELLER, J.; FINNEGAN, P.; MURPHY, C. (2003): "The Australian Prudential Regulation Authority: Managing regulatory complexity with XBRL", Prism: The measurement of intangibles. Case \#9.1.3.

FEDERAL DEPOSIT INSURANCE CORPORATION (2004): "Modernization of call report data management (Financial Institution Letter FIL-30-2004)", http://www.fdic.gov/news/news/financial/2004/fil3004.html

FINANCIAL ACCOUNTING STANDARDS BOARD. (2000): "Electronic distribution of business reporting information". Steering committee report series. Stamford, CT: FASB.

FOX, T. L.; SWANSON, Z.; REMINGTON, W. S.; DURLER, M. G.; HINDI, N. (2002): "An analysis of student XBRL project teams: Value-adding educational experiences using emerging technology", The Review of Business Information Systems, vol. 6, n. 3: 15-20.

THE FUTURIST (2003): “Technologies benefiting business", The Futurist, vol. 37, n. 2: 7.

GARSOMBKE, H.; CERULLO, M. (1984): “Auditing advanced computer systems", The EDP Auditors Journal, vol. 2, n. 1: 1-11.

HANNON, N. (2002): "XBRL makes progress worldwide”, Strategic Finance, vol. 83, n. 7: 61-62.

HARRINGTON, C. (2005): "The accounting profession: Looking ahead", Journal of Accountancy, vol. 200, n. 4: 43-48.

HASSON, F.; SINEAD, K.; MCKENNA, H. (2000): "Research guidelines for the Delphi survey technique", Journal of Advanced Nursing, vol. 32, n. 4: 1008-1015. http://dx.doi.org/10.1046/j.1365-2648.2000.01567.xPMid:11095242

HAYNE, S. C.; POLLARD, C. E. (2000): “A comparative analysis of critical issues 
facing Canadian information systems personnel: A national and global perspective", Information \& Management, vol. 38, n. 2: 73-82. http://dx.doi.org/10.1016/S03787206(00)00056-2

HODGE, F. D.; KENNEDY, J. J.; MAINES, L. A. (2004): "Does search-facilitating technology improve the transparency of financial reporting?", Accounting Review, vol. 79, n. 3: 687-703. http://dx.doi.org/10.2308/accr.2004.79.3.687

HOLSAPPLE, C. W.; JOSHI, K. D. (2001): "Organizational knowledge resources", Decision Support Systems, vol. 31, n. 1: 39-50. http://dx.doi.org/10.1016/S01679236(00)00118-4

HOLSTRUM, G.L.; MOCK, T. J.; WEST, R. N. (1986): "The impact of technological events and trends on audit evidence in the year 2000: Phase I", Auditing Symposium VIII. Proceedings of the 1986 Touche Ross-- University of Kansas Symposium on Auditing Problems, Lawrence, KS: University of Kansas: 125-146.

INSTITUTE OF CHARTERED ACCOUNTANTS IN ENGLAND AND WALES (1998): "The 21st Century Annual Report", ICAEW, London.

KEIL, M.; CULE, P. E.; LYYTINEN, K.; SCHMIDT, R. C. (1998): “A framework for identifying software project risks", Communications of the ACM, vol. 41, n. 11: 76-83. http://dx.doi.org/10.1145/287831.287843

KROENER, W. F. III. (2003): "Statement on the "Financial Services Regulatory Relief Act of 2003" before the Subcommittee on Financial Institutions and Consumer Credit of The Committee on Financial Services", U.S. House of Representatives. March 27, 2003. www.fdic.gov

LESTER, W. F. (2007): "XBRL: The new language of corporate financial reporting", Business Communication Quarterly, vol. 70, n. 2: 226-231. http://dx.doi.org/10.1177/108 $\underline{05699070700020603}$

LIN, F.; OLIVIA, R.; SHENG, L.; WU, S. (2005): “An integrated framework for eChain bank accounting systems”, Industrial Management \& Data Systems, vol. 106, n. 3: 291306. http://dx.doi.org/10.1108/02635570510590129

LINSTONE, H. A. (1985): "The Delphi technique", In (V.T. Covello et al., editors) Environmental Impact Assessment, Technology Assessment, and Risk Analysis. New York, NY: Springer-Verlag. 621-649.

LINSTONE, H. A.; TUROFF, M. (1975): "The Delphi method: Techniques and 
applications", Reading, MA: Addison-Wesley.

LOCKE, J.; LOWE, A. (2007): "XBRL: An (open) source of enlightenment or disillusion?", European Accounting Review, vol. 16, n. 3: 585-623. http://dx.doi.org/10.10 $\underline{80 / 09638180701507163}$

LYMER, A.; DEBRECENY, R.; GRAY, G.; RAHMAN, A. (1999): “Business reporting on the Internet", A report prepared for the International Accounting Standards Committee. IASC. London.

MARSHALL, B.; MORTENSON, K.; BOURNE, A.; AND PRICE, K. (2010): "Visualizing basic accounting flows: Does XBRL + model + animation = understanding?", The International Journal of Digital Accounting Research, vol. 10: 27 54. http://dx.doi.org/10.4192/1577-8517-v10_2

MCCOY, R. W. (2001): "Computer competencies for the 21st century information systems educator", Information Technology, Learning, and Performance Journal, vol. 19, n. 2: 21-35.

MCGUIRE, B. L.; OKESSON, S. J.; WATSON, L. A. (2006): "Second-wave benefits of XBRL”, Strategic Finance, vol. 88, n. 6: 43-47.

MURSU, A.; LYYTINEN, K.; SORIYAN, H. A.; KORPELA, M. (2003): "Identifying software project risks in Nigeria: an International comparative study", European Journal of Information Systems, vol. 12, n. 1: 182-200. http://dx.doi.org/10.1057/palgrave.ejis.3 $\underline{000462}$

PINSKER, R.; SHAOMIN, L. (2008): "Costs and benefits of XBRL adoption: Early evidence", Communications of the ACM, vol. 51, n. 347-50.

PINSKER, R.; GARA, S.; AND KARIM, K. (2005): "XBRL usage: A socio-economic perspective”, Review of Business Information Systems, vol. 9, n. 4: 59-72.

PINSKER, R. (2003): “XBRL awareness in auditing: A sleeping giant?" Managerial Auditing Journal, vol 18, n. 9: 732-736. http://dx.doi.org/10.1108/02686900310500497

RAMAMOORTI, S.; BAILEY, A. D. Jr.; TRAVER, R. O. (1999): "Risk assessment in internal auditing: A neural network approach", International Journal of Intelligent Systems in Accounting, Finance and Management, vol. 8, n. 3: 159-173. http://dx.doi.org/10.1002/(SICI)1099-1174(199909)8:3<159::AID-ISAF169>3.0.CO;2-W

REZAEE, Z.; SHARBATOGHLIE, A.; ElAM, R.; MCMICKLE, P. L. (2002): "Continuous auditing: Building automated auditing capability", Auditing: A Journal of 
Practice \& Theory, vol. 21, n. 1: 147-163.

REZAEE, Z.; TURNER, J. L. (2002): "XBRL-based financial reporting: Challenges and opportunities for government accountants", The Journal of Government Financial Management, vol. 52, n. 2: 16-22.

SCHMIDT, R.; LYYTINEN, K. ; KEIL, M.; CULE, P. (2001): "Identifying software project risks: An international Delphi study", Journal of Management Information Systems, vol. 17, n. 4: 5-36.

SECURITIES \& EXCHANGE COMMISSION. (2009): "Final rule: Interactive data to improve financial reporting", http://www.sec.gov/rules/final/2009/33-9002

SECURITIES \& EXCHANGE COMMISSION. (2000): "Final rule: Selective disclosure and insider trading", http://www.sec.gov/rules/final/33-7881.htm\#P12 1307

SHUETRIM, G.; SOMERVILLE, J. (2004): "Data management for credit risk - an XBRL equation”, Basel Briefing 7 (KPMG): 20-23.

SPAUL, B. (1997): "Corporate dialogue in the digital age", The Institute of Chartered Accountants in England and Wales, London.

STANTIAL, J. (2007): "ROI on XBRL”, Journal of Accountancy, vol. 203, n. 6: 32-35.

TEIXEIRA, A. (2005): "What XBRL means for IFRS”, Chartered Accountants Journal, vol. June: 53-54.

TRITES, G. (2004): "Decline of the age of Pacioli: The impact of E-Business on accounting and accounting education", Canadian Accounting Perspectives, vol. 3, n. 2: 171-186. http://dx.doi.org/10.1506/G82C-H0W9-L4TM-YJ94

TROSHANI, I.; RAO, S. (2007): "Drivers and inhibitors to XBRL adoption: A qualitative approach to build a theory in under-researched areas", International Journal of EBusiness Research, vol. 3, n. 4: 98-111.

VASAL, V. K.; SRIVASTAVA, R. P. (2005): "IT and web-based accounting, evidence from the Indian capital market", IIMB Management Review, vol. 17, n. 1: 79-85.

WAGENHOFER, A. (2003): "Economic Consequences of Internet Financial Reporting", Schmalenbach Business Review, vol. 55 n. October: 262-279.

XBRL. (2010a): "List of jurisdictions", XBRL.org. http://bit.ly/ay6cMt

XBRL. (2010b): "List of Members", XBRL.org. http://www.Xbrl.org/viewmembers 
XBRL. (2003): "XBRL-enabled accounting software solutions: A study",. XBRL Resource Center, white paper (Released on 5 August 2003): http://bit.ly/fE0UcV

XBRL JAPAN. (2005): Website: http:/ /www.xbrl-jp.org/

XIAO, Z.; JONES, M. J.; LYMER, A. (2002): "Immediate trends in Internet financial reporting"; European Accounting Review, vol. 11, n. 2: 245-275. http://dx.doi.org/10.108 $\underline{0 / 09638180020017087 \mathrm{a}}$

ZAREI, B. (2001): "Simulation for business process re-engineering: Case study of a database management system", The Journal of the Operational Research Society, vol. 52, n. 12: 1327-1339. http://dx.doi.org/10.1057/palgrave.jors.2601208 